\title{
Near optimum selection of module configuration for efficient modular construction
}

\author{
Osama MOSELHI ${ }^{1}$, and Tarek SALAMA ${ }^{2 *}$ \\ 1 Professor, Department of Building, Civil and Environmental Eng. ,Concordia University \\ 2 PhD student, Department of Building, Civil and Environmental Eng. ,Concordia University \\ Corresponding author's e-mail: salamatarek@gmail.com
}

\begin{abstract}
Modular construction has received considerable attention in recent years. This has been attributed to its impact on cost and time reduction and improved productivity and quality of constructed facilities. Modular construction can also result in improved safety on construction jobsites and reduced material waste. Most recent work in this field focused cranes selection and location, more suited scheduling methods and issues pertinent to logistics, without due consideration to optimized modules configuration. This paper introduces a newly developed unified modular suitability index to accomplish a near optimum selection of module configuration for efficient modular residential construction. The developed modular suitability index (MSI) utilizes five indices; 1) connections index (CI) that evaluates the module connections using the matrix clustering technique along with the bond energy algorithm, 2) transportation dimensions index (TDI) that accounts for the module dimensions' effects on transportation, 3) transportation shipping distance index (TSDI) to evaluate the distance between modules fabrication and assembly facility and the project construction site, 4) crane cost penalty index (CCPI) to evaluate the crane cost relevant to the module placing rate, and 5) concrete volume index (CVI) to evaluate the project's foundation concrete quantities. Calculating the modular suitability index (MSI) provides a unified indicator for the project stakeholders to assess the suitability of different modular configuration and support near optimum modules.
\end{abstract}

\section{KEYWORDS}

Modular and offsite construction; modularization; module configuration, suitability index.

\section{INTRODUCTION}

Modularization of residential and industrial projects has a great potential as an emerging technology after being utilized successfully in the shipbuilding and automotive industries. Advantages of modular construction were recognized several decades ago (e.g. Tatum et al., 1987) and more recently by O'Connor et al., (2014); investigating a set of critical success factors and enablers for optimum industrial modularization. Studying the critical success factors for modularization provided an overall idea highlighting needed changes in current engineering, procurement and construction (EPC) processes to support optimal use of modularization. These studies, however, did not provide a systematic process to quantify the degree of modularity between different modular construction projects. This paper provides a novel methodology for near optimum selection of module configuration. The methodology addresses the lack of 
knowledge by architects about the limitations of the manufacturing process of the modules, which was identified in an earlier study (Schoenborn, 2012). The developed methodology is accomplished by considering a set of practical constraints and factors that affect the module configuration such as the connections limitation, transportation and weights limitations, crane cost limitation, and the required concrete quantities for project foundation.

\section{PROPOSED METHODOLGY}

As stated earlier, the developed methodology utilizes five indices, which accounts for connections of modules onsite (CI), transportation of fabricated modules to construction jobsite (TDI and TSDI), crane operating condition and related cost (CCPI) and project concrete foundation (CVI). Each index is describes below.

\section{CONNECTIONS INDEX (CI)}

Reducing the number of modules (boxes) in any modular construction project is cost efficient as long as the transportation limitations are satisfied. This is because increasing modules connections increases construction and maintenance costs and requires more lifts by the crane as well as more trucks for transportation. Hence investigating the types and costs of different module connections along with their locations is essential in identifying and comparing the suitability of modular design and configuration of modules. Figure 1 illustrates the differences of connections between two modular designs identical in the plan area and each of them has three stories. For the example considered, design A comprises 18 modules as indicated in Table 1, which requires 18 truckloads and would take two days for the crane onsite to set them into their positions. Design B, however, is comprised only of 9 modules, which require only 9 truckloads and would take only one day for the crane onsite to set them into their final positions. Hence analyzing the connections cost, number of transportation trucks, and the crane cost are required for cost efficient configuration of the modules.

\section{Analyzing module connections using the matrix clustering technique}

The proposed connections index is assessing the modular suitability through evaluating the connections in each modular design. The aim is to identify the module with fewer connections. Matrix clustering technique is used in this paper to analyze the interdependencies between modules after configuring the connection types that connect them. These matrices data are reorganized to cluster modules with large mutual importance. This importance is necessary for project stakeholders in assigning priority to some module interfaces regarding materials and budget allocation. This technique was used in a previous study to identify the modularity advantages for nuclear power plants (Lapp and Golay, 1997). However, in this paper the matrix clustering technique creates an interface cost penalty matrix for residential modules as per the following steps:

1- Arbitrary cost penalties were assigned hypothetically to demonstrate the use of the developed methodology. Penalties assigned to each connection type are included in Table 2 to quantify modules interfaces' connections.

2- Multiplying all the identified connections by their assumed arbitrary cost penalty for all the modules interfaces to reach the unclustered cost penalty matrix. 

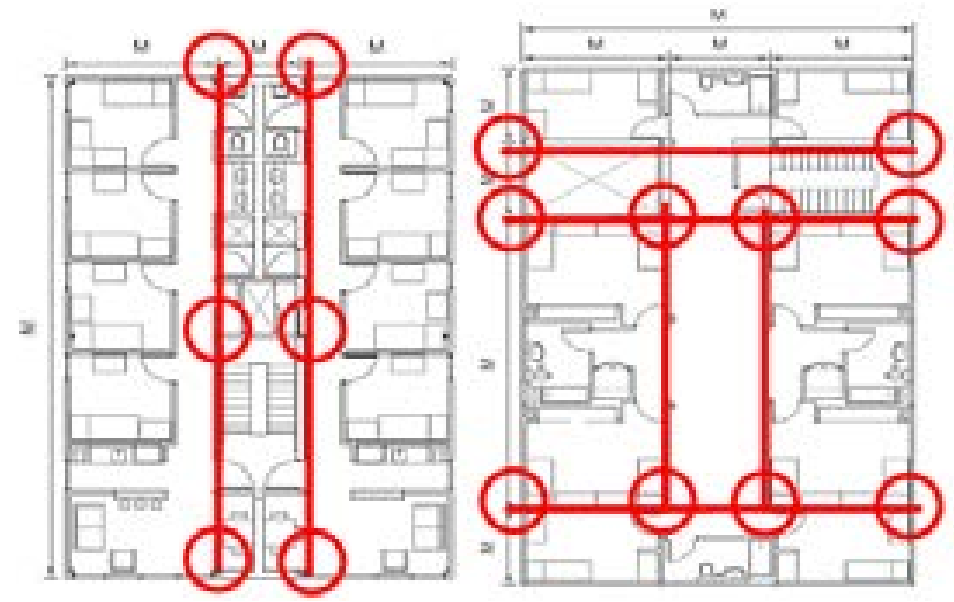

Figure 1. Design A to the right, design B to the left (Garrison and Tweedie 2008).

\begin{tabular}{|c|c|c|c|c|c|c|c|c|}
\hline \multicolumn{3}{|c|}{ First Floor } & \multicolumn{3}{|c|}{ Second Floor } & \multicolumn{3}{|c|}{ Third Floor } \\
\hline \multicolumn{3}{|c|}{1} & \multicolumn{3}{|c|}{7} & \multicolumn{3}{|c|}{13} \\
\hline \multicolumn{3}{|c|}{2} & \multicolumn{3}{|c|}{8} & \multicolumn{3}{|c|}{14} \\
\hline 3 & 4 & 5 & 9 & 10 & 11 & 15 & 16 & 17 \\
\hline \multicolumn{3}{|c|}{6} & \multicolumn{3}{|c|}{12} & \multicolumn{3}{|c|}{18} \\
\hline
\end{tabular}

Table 2. Connections Codes and its Arbitrary Cost Penalty.

\begin{tabular}{c|c|c}
\hline Connection & Code & Arbitrary Cost Penalty \\
\hline External connection & 1 & 20 \\
\hline Internal connection & 2 & 15 \\
\hline MEP connection & 3 & 10 \\
\hline Vertical circulation connection & 4 & 20 \\
\hline Corner connection & 5 & 10 \\
\hline
\end{tabular}

3- Reordering the rows and columns of the unclustered matrix to cluster the array of connections' cost penalties having large values. This task is accomplished by multiplying an element a(ij) of the matrix by the sum of elements surrounding it to the left, right, top and bottom (McCormick et al., 1969). Then, summing over columns (or rows) of the multiplications to acquire the bond energy algorithm (BEA) value. Afterwards the rows and columns are reordered within the matrix until this reordering gives the largest value of the BEA. Knowing that the 
optimal matrix clustering is obtained by maximizing the measure of effectiveness (ME), where the ME is identified as follows:

a- Assuming that the relationships matrix's dimension $\mathrm{M}$ by $\mathrm{N}$ with non-negative elements a(ij). b- Identifying the quantity A (ij) as indicated in the following equation:

$A_{i j}=0.5 \times\left[a_{i+1, j}+a_{i-1, j}+a_{i, j+1}+a_{i, j-1}\right]$.

c- Identifying the measure of effectiveness (ME) as indicated in the following equation:

$M E=\sum$ All $i, j\left\lfloor a_{i j} \times A_{i j}\right\rfloor$

4- Representing the final clustered matrix as presented in Table 3.

\section{Analyzing the results of clustering}

The results of the modules' connections cost penalty clustering analysis shown in Table 3 can be used to determine the costly connections locations in an attempt to reduce the costs associated with their most important characteristics as well as prioritizing the resource assignment to certain connections depending upon its priority. Hence such technique can be very useful in analyzing the connections attributes in more complex modular construction projects, since the modules which are connected functionally shall be grouped together. This priority can be noticed when comparing the clusters of modules number 2, 7,8,13 and 14 to the clusters of modules 16 and 18 . Since the first clustering group has higher connections cost penalty values than the second clustering group, and its clustering group area is bigger. Hence it requires more attention towards its cost and construction.

\section{Calculation of the Connections Index (CI)}

This paper presents a connections index (CI) to account for connections quantity as well as modules' connections cost implications to compare between different modular construction designs and identify suitability of design and configuration of project modules. This Index is simply the summation of the calculated arbitrary cost penalties. Hence it is the summation of half the arbitrary cost penalties indicated in the symmetrical clustered matrix.

$\mathrm{CI}=\sum$ connections cost penalties

\section{TRANSPORTATION DIMENSIONS INDEX (TDI)}

In the last two decades, modular construction industry has rapidly gained momentum with the help of advanced computer aided modelling and the new capacities of heavy lift cranes. This allowed constructing larger modules as needed. It is ideal to minimize the number of modules (boxes) that should be built for any modular construction project. Since the most cost efficient module is the largest module that could be transported with the most amounts of interior finishes. Hence designing fewer larger modules would be better than smaller modules because there is less cost when getting more square footage per truckload (Cameron and Carlo, 2007). Furthermore, size constraints should be clarified during the initial design stage as well as its associated weight constraints which will control the shipping method and route of transportation. Currently there are many ways of transporting manufactured modules as trucks/trailers, railways, and ships, though the mostly used way of transportation are the trucks. Accordingly, trucks and their related constrains will be considered in the developed methodology. There are three standard types of trailers used to transport manufactured modules as follows (Smith, 2010): 


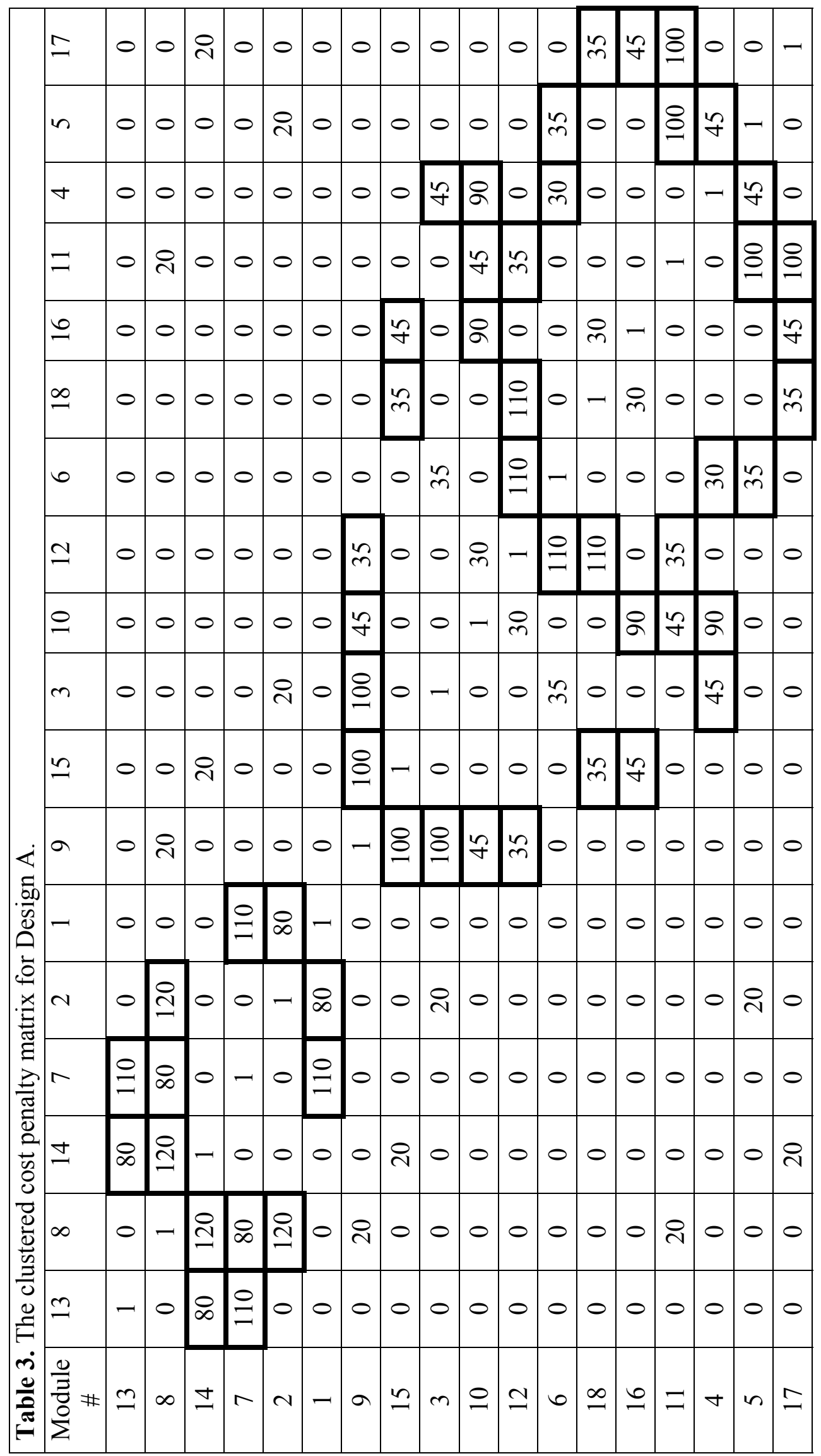


1- Standard Flatbed trailer: This is a two-axle trailer used when weight and height are not an issue. The trailer bed is $8 \mathrm{ft}-6$ in. wide and $48 \mathrm{ft}$ long, though the maximum module height is limited to $8 \mathrm{ft}-6$ in because the bed is so high off the ground. Using this trailer, the module maximum weight is $48,000 \mathrm{lbs}$.

2- Single-drop deck/ trailer: This trailer can be two or three axles which has a single-drop deck. In a triaxle single-drop deck trailer, the module length can reach $50 \mathrm{ft}$., width of 13 $\mathrm{ft}$., and height of $12 \mathrm{ft}$. Using this trailer the module maximum weight ranges from 44,000 to $45000 \mathrm{lbs}$.

3- Double-drop deck/ trailer: This trailer is known in the market as the "lowboy," and its main advantages that it is able to transport higher loads without permitting as well as providing extra feet of height for modules due its lower bed. The module length can reach $40 \mathrm{ft}$., width of $13 \mathrm{ft}$., and height of $15 \mathrm{ft}-6$ in.

For a practical optimization of the modules dimensions, these trailers dimensions limitations should be integrated with the commercial trucking regulations such as those stipulated by two agencies in the USA. The first is at the federal level (Federal Size Regulations for Commercial Motor Vehicles); U.S. Department of Transportation, Federal Highway Administration (FHWA) and the second is at the state level. These regulations include two module dimensions, the first is the usual transportation dimensions without requiring any permits or escorts and the second is the maximum possible module dimensions which requires permits or escorts, which will affect the transportation cost significantly. Choosing the optimum module dimensions would better consider the usual transportation dimensions without adding extra transportation costs due to the need for permits or escorts. Considering the cost of renting the three standard types of trailers depicted in Figure 2, the least trailer's rental cost would be the standard flat bed trailer, then renting the single-drop deck would cost higher; and then renting the double-drop deck is higher than the previous two trailers. Moreover the standard flat bed trailer might enable a better length for module transportation though its limitations regarding module width and height makes the single-drop deck a better alternative.

Although the double-drop deck would allow the modules to have a heavier weight and an extra one feet of module height, it has the same width limitation as the single-drop deck and its allowable module length is less than the single-drop deck trailer by 10 feet as well as it has higher cost among all trailers. Hence the single-drop deck is the most commonly used alternative between the three types of trailers for modules transportation, unless the module has over weight components, in that case the double-drop deck would be the best alternative. The optimum residential modules' dimensions generated by the proposed methodology, based on the aforementioned facts as well as considering the modular builders contribution to "the guide to modular design and construction" (Smith, 2010) are presented in Table 4. Developing an index to reflect the module's optimality is essential for the modular construction process of the project which consists of multiple modules with different dimensions according to the architectural and structural needs.

This developed index should indicate the module's dimensions relevance to the optimum module dimensions in conjunction with the cost of module's square footage per truckload and the number of modules in the project.

$$
\mathrm{TDI}=\frac{1}{\text { numberof modules }} \times \sum \frac{\text { proposed module design square footage cost per truckload }}{\text { optimum module square footage cost per truckload }}
$$




\begin{tabular}{c|c|c}
\hline Table 4. The optimum residential modules' dimensions. \\
\hline Dimensions & $\begin{array}{c}\text { Common } \\
\text { Maximum }\end{array}$ & $\begin{array}{c}\text { Oversized } \\
\text { Maximum }\end{array}$ \\
\hline Module Width & $13 \mathrm{ft}$ & $16 \mathrm{ft}$ \\
\hline Module Length & $52 \mathrm{ft}$ & $60 \mathrm{ft}$ \\
\hline Module Height & \multicolumn{2}{|c}{$12 \mathrm{ft}$} \\
\hline
\end{tabular}
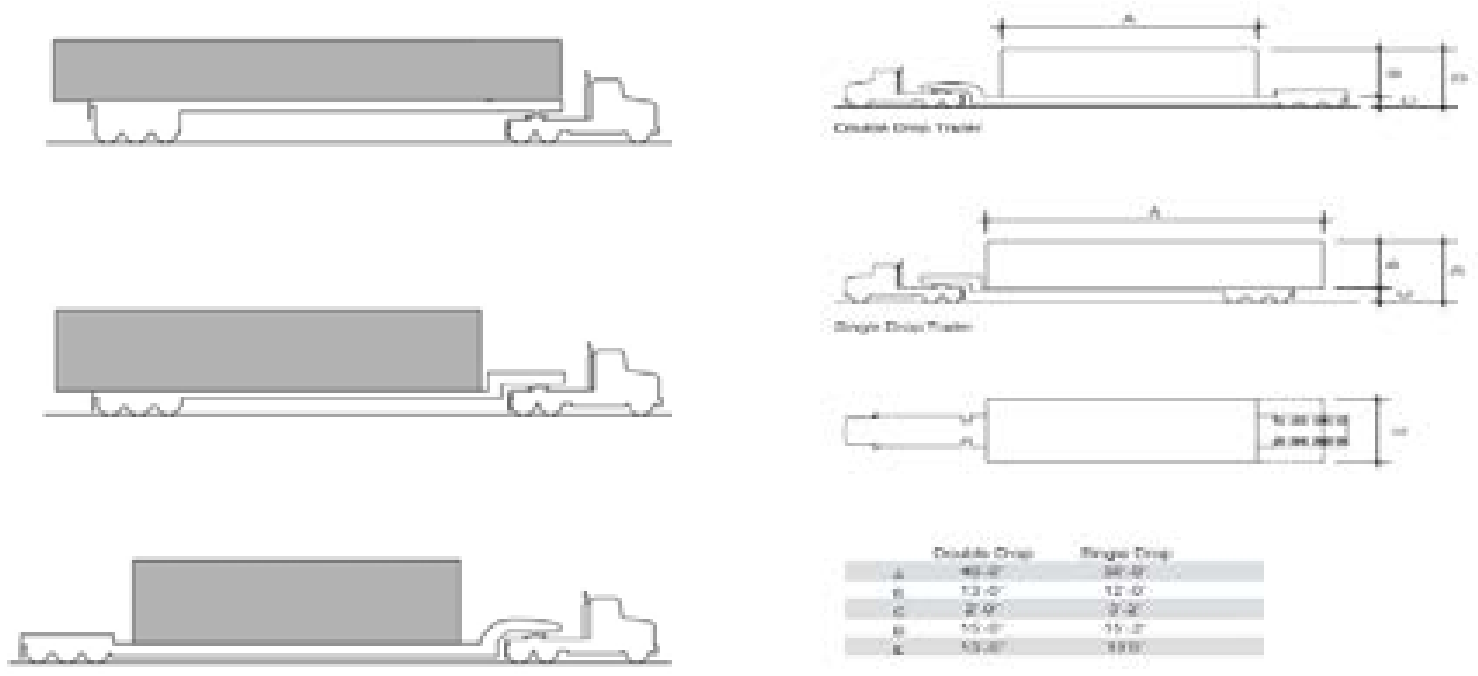

Figure 2. The three standard types of Figure 3. Generalized trailers and modules trailers used to transport modules: Top: limiting dimensions (Garrison and standard flat bed trailer, Middle: single- Tweedie, 2008). drop deck; and Bottom: double-drop deck (Smith, 2010).

\begin{tabular}{|c|c|c|c|}
\hline Sesa & Wioth & Haight & Lereth \\
\hline Nabara & $12(16)$ & $\cdot(15)$ & $76(150)$ \\
\hline Arika & $10(2)$ & 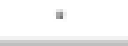 & $100(\%)$ \\
\hline Nives & $11(14)$ & $\cdot(16)$ & $\cdot(120)$ \\
\hline Nkansas & $12(20)$ & $15(17)$ & $90(7)$ \\
\hline Callonis & $12(15)$ & $\cdot(17)$ & $85(185)$ \\
\hline Colgade & $11(17)$ & $13(16)$ & $85(130)$ \\
\hline Cornecticut & $12(16)$ & $14\left({ }^{\circ}\right)$ & $80(120)$ \\
\hline Delswase & $12(15)$ & $15(17-6)$ & $85(120)$ \\
\hline Distra ofColurnba & $12(7)$ & $18-6(7)$ & $80\left(0^{\circ}\right)$ \\
\hline Fonsis & $12(16)$ & $14 \cdot 6(18)$ & 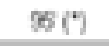 \\
\hline Corgata & $12(15)$ & $15-6(7)$ & 567 \\
\hline Istaho & $12(16)$ & $14-6(16)$ & $150(120)$ \\
\hline
\end{tabular}

\begin{tabular}{|c|c|c|c|}
\hline Staes & Wath & Height & Lenoh \\
\hline Morten & $12-6^{\prime}(18)$ & * (17) & $"(120)$ \\
\hline Nebrasha & 180 & $14-6(7)$ & $S(7)$ \\
\hline Nevada & $8 \cdot 6^{\circ}(17)$ & $\cdot(16)$ & $106(\mathrm{C})$ \\
\hline New Furpshins & $12(16)$ & $13-6(16)$ & $80(100)$ \\
\hline New Jesty & $4(18)$ & 16 (96) & $100(120)$ \\
\hline Now Mexico & $\cdot(20)$ & $\cdot(18)$ & $*(190)$ \\
\hline New York & $12(14)$ & $14(7)$ & $80\left(0^{\circ}\right)$ \\
\hline Noth Cardina & $18(15)$ & $14-5(7)$ & $100(7)$ \\
\hline Non Dakata & $14-6^{*}(18)$ & $\cdot(18)$ & $75(120)$ \\
\hline Ohis & $14(7)$ & $14.10^{\circ}(7)$ & $90\left({ }^{\circ}\right)$ \\
\hline Olingena & $12(16)$ & $\cdot(17)$ & $80\left(0^{\circ}\right)$ \\
\hline Orogon & $9(16)$ & * & $\%(7)$ \\
\hline
\end{tabular}

Figure 4. Allowable module dimensions Regulations for truck transportation according to the state (Garrison and Tweedie, 2008).

* () indicates maximum possible dimension requires permits or escorts. 


\section{TRANSPORTATION SHIPPING DISTANCE INDEX (TSDI)}

Another index is developed relating to transportation and logistics which is the Transportation Shipping Distance Index (TSDI). This index indicates the effect of shipping distance from the offsite fabrication/assembly facility to the construction site on the module transportation cost. Several studies indicate that the industry generally recognizes 125 miles as the maximum practical distance for modules to travel from factory to site (Smith, 2010). Moreover, shipping modules becomes cost prohibitive when they travel more than 150 to 200 miles from the manufacturing facility to the construction site. In the case of offsite modules having a width of $12 \mathrm{ft}$ or greater, transportation cost increases exponentially (Smith, 2010).

Furthermore, these studies indicate an average cost for transporting modules that has a width of 8.5 to $12 \mathrm{ft}$ to be $\$ 3.27 / \mathrm{S}$.F. while the average cost for modules with a width greater than $12 \mathrm{ft}$ was $\$ 5.00 / \mathrm{S}$.F., however these average costs reflect the average of module transportation without including the cost associated with the distance between the manufacturing facility to the construction site. Hence this cost estimate can be used to choose between different manufacturing facilities for supplying modules to the construction site based on their distance from the construction site.

The transportation shipping distance index (TSDI) assumes the practical transportation distance of 125 miles to be the optimum transportation distance having the average transportation cost of $\$ 5.00 / \mathrm{S}$.F and an optimum transportation value of 1 . Any transportation distance up to 200 miles should have a transportation value which is linearly proportional to this optimum transportation value.

$\mathrm{TSDI}=\frac{\sum \text { transportation value } \times \text { averagetranspotation cost perS.F } \times \text { module squarefootag } \epsilon}{\text { numberof modules }}$

\section{CRANE COST PENALTY INDEX (CCPI)}

A rule of thumb in choosing the right crane for a modular construction project is to choose a small and accessible crane to lift multiple modules rather than choosing a large crane to lift one or two lifts. Choosing the right crane requires a comprehensive study for many variables as indicated in a number of previous studies (Al-Hussein et al., 2005 and Han, 2014) such as the required lifting capacity, working radius, lifting height, clearances, and optimal crane path. Generally modular construction of buildings would require a crane with a capacity of 40 to 75 tons, depending on design (Garrison and Tweedie, 2008). Choosing the right crane requires the definition of the average weight of modules per square feet as well as the largest module onsite which will definitely control the crane capacity.

The regular traditional modules weight ranges from 10 to 25 tons depending on their floor size (Velamati, 2012). Knowing that the modules placing rate per day (i.e. speed of construction) is different from project to another, this rate can be 7 modules per day (Velamati, 2012), or 8 modules a day as considered by a Seattle-based modular fabrication facility. In other cases estimates of 10-12 modules per day were considered (Azari, 2013). This placing rate depends on the module dimensions, the site constraints, as well as the weather conditions.

The Crane Cost Penalty Index (CCPI) accounts for the crane cost per module, taking into consideration the cost of renting the crane per day including mobilization and 
demobilization costs, the daily module placing rate, and the number of modules in the project as follows:

$\mathrm{CCPI}=\frac{\text { Crane renting cost per day } \times \text { number of project modules }}{\text { daily module placing rate }}$

\section{CONCRETE VOLUME INDEX (CVI)}

This index accounts for the quantities of concrete for the foundation, and is referred to in this paper as concrete volume. For example wood framing in housing construction commonly transfers the load to the foundation uniformly and can result in strip footings. On the other hand structural steel framing may lead to isolated or even mat foundation, Smith (2010) stated that foundations for modular construction can either be piers, linear footings, or continuous footings.

This paper presents the Concrete Volume Index (CVI) which evaluates the suitability of a modular design based on the required concrete volume. The CVI accounts for the volume of concrete used in the project's foundations and relates it directly to the cost of the project. The equation constructed to calculate the CVI is:

$\mathrm{CVI}=$ total concrete volume $\times$ concrete cost per unit volume

\section{MODULAR SUITABILITY INDEX (MSI)}

The modular suitability index (MSI) integrates the above mentioned five indices into one unified index to be used as an indicator of the modular suitability based on reducing the economic implications of different project costs. Modular construction cost needs considerable attention to the process of suitability evaluation of different modular design configurations. The integrated MSI is calculated using the weighted sum expressed by: $\mathrm{MSI}=(\mathrm{A} 1 \times \mathrm{CI})+(\mathrm{A} 2 \times \mathrm{TDI})+(\mathrm{A} 3 \times \mathrm{TSDI})+(\mathrm{A} 4 \times \mathrm{CCPI})+(\mathrm{A} 5 \times \mathrm{CVI})$

In which A1 to A5 are relative weights that account for the preference of the project stakeholders.

\section{CONCLUSION}

This paper presented a newly developed methodology to support the process of identification and selection of near optimum module configurations accounting for project conditions. The developed Modular Suitability Index (MSI) provides quantitative assessment of the suitability of module design configurations for building construction. It integrates the effect of five newly developed indices; connections index (CI), transportation dimensions index (TDI), transportation shipping distance index (TSDI), crane cost penalty index (CCPI), and concrete volume index (CVI). The optimum practical module dimensions were identified based on transportation and weight constraints. Finally it was concluded that reducing the number of module connections shall be cost efficient as long as transportation and weight limitation are satisfied. 


\section{ACKNOWLEDGEMENTS}

The authors wish to thank Dr. Hany Elsawah and Dr. Ibrahim Bakry for their comments and review of the manuscript of this paper.

\section{REFERENCES}

Al-Hussein, M., Alkass, S., and Moselhi, O. (2005). "Optimization algorithm for selection and on site location of mobile cranes." J. Constr. Eng. Manage., 579-590.

Azari, R., (2013). "Modular Prefabricated Residential Construction Constraints and Opportunities." PNCCRE Technical Report \#TR002, University of Washington.

Cameron, P. J., Jr. and Carlo, N. G. D. (2007). "Piecing together modular: understanding the benefits and limitations of modular construction methods for multifamily development" Master of Science thesis in real estate development, Dept. of Architecture, Massachusetts Institute of Technology, USA.

Garrison, J., and Tweedie, A. (2008). "Modular Architecture Manual". Kullman Buildings Corporation and Garrison Architects.

Han, S. H. (2014). "BIM-based Motion Planning of Mobile Crane Operation in Modular-based Heavy Construction Sites." Doctor of Philosophy (PhD), University of Alberta, Canada.

Lapp C. W., and Golay M. W. (1997). "Modular design and construction techniques for nuclear power plants." Journal of Nuclear Engineering and Design, Volume 172, Issue 3, Pages 327-349.

McCormick Jr., W.T., Deutsch, S.B., Martin, J.J., Schweitzer, P.J., (1969). "Identification of Data Structures and Relationships by Matrix Reordering Techniques." Research Paper P-512, Institute for Analyses.

O'Connor, J., O'Brien, W., and Choi, J. (2014). "Critical Success Factors and Enablers for Optimum and Maximum Industrial Modularization." J. Constr. Eng. Manage., 140(6), 04014012.

Schoenborn, J. M. (2012). "A Case Study Approach to Identifying the Constraints and Barriers to Design Innovation for Modular Construction." Master of Science in Architecture, Faculty of the Virginia Polytechnic Institute and State University.

Smith, R. E. (2010). "Prefab Architecture: A Guide to Modular Design and Construction" Wiley Publications, ISBN: 978-0-470-27561-0, 400 pages.

Tatum, C. B., Vanegas, J. A., and Williams, J. M. (1987). "Constructability improvement using prefabrication, preassembly, and modularization." Univ. of Texas, Construction Industry Institute, Austin, TX.

Velamati S. (2012). "Feasibility, benefits and challenges of modular construction in high rise development in the United States: a developer's perspective." Master of Science thesis in real estate development, Dept. of Architecture, Massachusetts Institute of Technology, USA. 